\title{
Grupo interdisciplinar STI_USAL de innovación en ciencias, tecnología, ingeniería y matemáticas
}

\author{
María Dolores Merchán Moreno; Cristina Prieto Calvo; \\ María Jesús Santos Sánchez
}

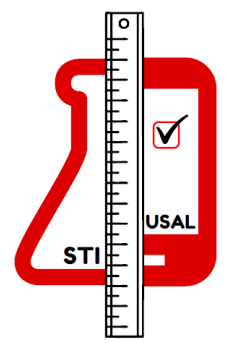

4

L GRUPo INTERDisCiPLINAR de Innovación en Ciencias, Tecnología, Ingeniería y Matemáticas (STI_USAL) está formado por profesoras de la especialidad de Física y Química del Máster Universitario de Profesor de Educación Secundaria Obligatoria y Bachillerato, Formación Profesional y Enseñanzas de Idiomas (MUPES), y surgió para la coordinación de la docencia de las asignaturas de Máster.

Posteriormente la actividad del grupo ha evolucionado hacia el intercambio de experiencias innovadoras cristalizando en la constitución de un grupo de investigación en innovación docente en Ciencias, Tecnología, Ingeniería y Matemáticas.

Los objetivos planteados son:

1. Coordinar la labor docente dentro del Máster para dar mayor coherencia a las propuestas de innovación docente presentadas.

2. Compartir entre los miembros del Grupo las experiencias de innovación realizadas con los estudiantes de Grado.

3. Hacer un análisis crítico de los resultados obtenidos con las diferentes metodologías o propuestas innovadoras.

4. Revisar conjuntamente de forma semestral los resultados obtenidos con los proyectos que se estén desarrollando y tomar decisiones al respecto.

5. Participar en actividades de divulgación: congresos y publicaciones científicas. 
En cuanto a las actividades desarrolladas por el Grupo y los logros conseguidos destacan:

- Impartición de forma coordinada de las asignaturas de la parte específica del MUPES.

- Participación conjunta en PIMD de la USAL.

- Elaboración de un blog personal por cada uno de los estudiantes con la herramienta Diarium (http://diarium. usal.es/smjesus/enlaces-2/).

- Realización de actividades de utilización de dispositivos móviles en el aula para hacer medidas de magnitudes

La creación del Grupo de trabajo proporciona un marco ideal para el intercambio de experiencias innovadoras.

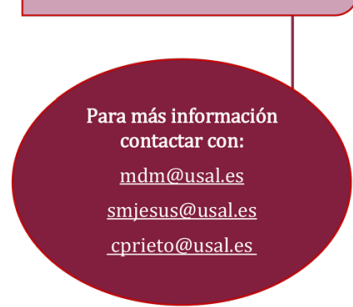
físicas.

- Iniciación de los estudiantes en la investigación educativa mediante la dirección de TFM del MUPES.

- Utilización de Socrative con los estudiantes de grado para apoyar la evaluación continua, y con los de máster para evaluar la práctica docente.

En cuanto a los resultados obtenidos con esta práctica:

1. Evaluación positiva de los estudiantes de MUPES de tres materias: Didáctica, Evaluación e Innovación docente.

2. Canal de YouTube donde se comparten las distintas experiencias.

3. Blogs de los estudiantes como portafolio de aprendizaje.

4. Comunicaciones en diferentes congresos y publicaciones de innovación docente.

5. Alto grado de interiorización del trabajo colaborativo y las TIC en el aula por parte de los alumnos.

6. Tutorización de TFM en innovación docente, atención a la diversidad y desarrollo sostenible con altas calificaciones.

Las innovaciones que se presentan son:

- Coordinación entre las asignaturas del máster, demandada y valorada por los estudiantes.

- La incorporación de TIC en el desarrollo de la docencia, de la metodología de clase invertida, la tutoría entre compañeros/as, etc.

Los TFM y PIMD desarrollados durante los últimos 8 años han dado lugar a comunicaciones en congresos científicos y a la publicación de dos libros y dos capítulos de libro. 